\title{
BLAST RESISTANT DESIGN OF STRUCTURE
}

\author{
Sajal Verma ${ }^{1}$, Mainak Choudhury ${ }^{2}$, Purnachandra Saha ${ }^{3}$ \\ ${ }^{1,2}$ Student, School of Civil Engineering. KIIT University, Bhubaneswar, Odisha, India \\ (Email: sajal.verma6@gmail.com,m.chow1993@gmail.com) \\ ${ }^{3}$ Senior Associate Professor, School of Civil Engineering. KIIT University, Bhubaneswar, Odisha, India \\ (Email: dr.purnasaha@gmail.com)
}

\begin{abstract}
Blast is a wave of highly compressed air spreading outwards from an explosion. Blast attacks by terrorists, and domestic accidents like LPG gas cylinder bursts have become a concern due to their increased frequency and fatal effect on lives and properties. So it has been a paramount importance to design structures which can resist blast effect better, so that destruction is controlled in a better way. In this paper an attempt is made to review the various methods applied to different types of structure, such as, masonry, concrete, steel and the effectiveness of each method. The Indian code does not have enough provisions for dealing with blast load, so it is important to study the properties of blast loading as dynamic loading. The various methods discussed are FRP retrofit technique in masonry walls, unidirectional passive dampers in steel structures, varying core density in sandwich structures and composites materials. it is observed that FRP retrofit technique in blast protection and steel structure with passive dampers are effective as blast resistance technique since no visible damage, crack, or debonding occurred in any of the walls and steel structure as the internal energy is mainly dissipated by the dampers.
\end{abstract}

Keywords: Blast loading; Fiber reinforced polymers; Masonry; Damper; Sandwich structures; Blast protection.

\section{INTRODUCTION}

In present times due to the frequent menaces of the terrorists by blast attacks it has been necessary to design strategically important structures such as government or military facilities in such a way that they palliate blast effects and defend the structures. It is also seen that domestic accidents such as bursting of gas cylinders are also very common, so there is a need to design the structure in such a way that the accidental injuries are minimum. Blast is an annihilative wave of highly compressed air circularizing from an explosion. If a structure lacks in adequate strength and ductility it can fail when subjugated to blast pressure often yielding flying debris which can cause serious injuries. So it is essential to demonstrate various strategies for blast response mitigation ${ }^{1}$.

In this paper the dynamic properties of blast loading such as natural period of vibration, strain rate effect were studied. Extensively used techniques for increasing the blast resistance of structure are FRP, sandwich panels, dampers, polymer sprays etc. The following Fiber Reinforced Polymers (FRP) generally used are i.e. Carbon Fiber reinforced polymer (CFRP), Glass Fiber reinforced polymer (GFRP) and High Strength Fiber reinforced polymer (SFRP). The FRP adheres to the concrete and bounds it laterally and has been found useful in enhancing the blast resistance of structures. Dampers have the capacity to resist both seismic and blast loads. Sandwich structures due to their light weight and blast resisting characteristics are being used in a wide range of structures ${ }^{3}$.

\section{BLAST LOADING}

Blast loading in the nearby areas consists of earth shock, pressure due to blast and affect of debris or fragment whereas blast loading in the distant areas consists of pressure generated due to blast only. Blast overpressure is showed comparative to ambient consideration (P0) instead of the absolute pressure. The distinctiveblast caused pressure wave analysis, developed from the perfect explosion including the various loadings related to frequency and amplitude is shown in fig. 1.Representation of the blast wave and its properties are dependent on time $(\mathrm{t})$, the length between structure and midpoint of the charge, R. Ppos is the summit pressure and is cognized as peak positive overpressure. During the negative phase the pressure is Pneg and is cognized as underpressure, as Pneg is less than P0.The continuance of Ppos and Pneg are cognized as tpos and tneg respectively, where tpos is the positive duration and tneg is the negative duration 1 .

\subsection{Blast Response Mitigation}

The two primary goals for designing a structure resistant to blast are: (1) to restrict the structural damage to a satisfactory range and (2) capability of a structure to function after blast. The most economic and effective scheme is to increase the length between structure and midpoint of the chargewhich is also known as the standoff distance. This strategy is effective as the blast waves disintegrate rapidly and the blast pressure decreases with increase of standoff distance. Proper apportioning of mass is the second factor influencing blast resistance design, if the weight is placed schematically then it results increased energy absorption when subjected to blast loading. Studying 
and regarding these two arguments, appropriate materials may be applied suitable strategies may be used to design a structure for palliating blast response 1 .

\subsection{Effectof Shape of Buildings on Blast Pressure}

The design blast load is affected by dimensions and shape of the structure. Reflections are to be fended off for reducing the design blast load. If a structure has a rectangular boundary or square boundary then at the middle of the open edges normal reflections are produced, constant summit reflected pressures are created along the long sections and close to the quoins of the structure steady reflections exists. For a structure of circular shape the maximum summit reflected overpressure is detected at a point lying on the boundary line, which is closest to the explosion.

A cube shape or a parabola shaped face of a structure has lower blast pressure than a vertical facade with no slope.Cylindrical structures have higher summit overpressures than cubical structures. Convex shaped facades are preferred over concave shaped facades in blast response palliation 1 .

\subsection{Dynamic Properties of Blast Loading}

Blast loading being dynamic in nature is different from normal static loading, so the properties of dynamic loading need to be studied in order to design a blast resistant structure 3 .

\subsubsection{Strain Rate Effect}

Blast loading is employed rapidly on the structures causing a hike in theresistance of the material, which is not observed in case of static loading. This increase is known as strain rate effect. The strain rate increased to 1.19 times under flexural action is accepted3.

\subsubsection{Natural Period of Vibration}

It decidesthe maximum transient deformation of the wall for a certain duration of the loading of certain blast strength.The natural period of vibration is represented by the following equation3.

$$
T_{n}=\frac{2 \pi}{\omega}=2 \pi \sqrt{\frac{K_{L M} M}{K_{E}}}(1)
$$

Where, $\mathrm{K}_{\mathrm{LM}}=$ Load mass factor, equal to 0.63 for two-way elements simply supported on four sides; $\mathrm{M}=$ actual mass of the structure; $\mathrm{K}_{\mathrm{E}}=$ equivalent elastic stiffness; and $\omega=$ natural circular frequency with aspect ratio between 1 and 2 (U.S. Department of Army 1990).

\subsubsection{Dynamic Load Factor}

DLF is utilized for the determination of dynamical reaction of a linear elastic mechanism using the static response. The ratio of the equivalent static load and peak load is known as dynamic load factor(DLF), which is utilized to find out dynamic to static effects and determined by the following equation3.

$$
D L F=\frac{R_{S}}{P}
$$

Where, $\mathrm{P}=$ peak load, $\mathrm{R}_{\mathrm{S}}=$ equivalent static load.

\section{BLAST RESISTSNCE TECHNIQUES USED IN STRUCTURES}

Different types of techniques are used for blast resistance in masonry, concrete and steel structures. The methods which may be utilized for the blast resistance of these structures are discussed separately.

\subsection{Masonry Structures}

A heavy explosion effects the structural solidification or strengthening of vital establishments, such explosions have become common in the late years6. If the blast explodes close to the building then the effect on the building may depend on the exterior walls and windows1.Since under the blast effect most traumas are caused by dissolution and fragmentation of masonry walls. So it is very important to improve the blast resistance of a wall. By increasing the mass and ductility of the wall with additional steel and concrete reinforcement one can increase the blast resistance of the wall6. But this method of increasing the mass of the wall is uneconomical, so there is a necessity to find economical and effective methods of reinforcing existing concrete and masonry walls5.

The structural behavior of a completely grouted reinforced concrete masonry walls exposed to dynamic loading were studied. Blast resistant masonry wall will usually be reinforced and fully grouted. The required ductility to prevent collapse is provided by the reinforcement and the internal resistance is maximized by full grouting of the structure.Masonry walls can be classified as single Wythe or multiwythe. The latter is further divided as composite or non composite.In case of composite walls, the Wythe of the wall behave unitedly as one unit but in case of non-composite walls(cavity walls) all the wythes act as individual separate units. Cavity walls is an alternative name of non composite multiwythe construction. When the external Wythe of a cavity wall fulfills the purpose of non-structural facade only then it is cited as veneer wall. Internal CMU (Concrete Masonry Unit) structural Wythe along with an external brick veneer are the parts of a veneer wall2.

Hwee Tan and Patoary utilized approximate analysis method for determination of blast resistance in masonry structures reinforced with FRP. The fundamentals of Dynamic load factor (DLF), strain rate analysis, Single degree of freedom (SDOF) model were blended to determine the blast resistance characteristics of the FRP. Tests were done on eighteen masonry walls reinforced with various types of FRP systems. Numerical models were prepared using CONWEP for prediction of the blast overpressure and the specimens were designed accordingly.Few specimens were designed to undergo deformation up to the plastic range but in contrary it was found that no specimen crossed the elastic 
limit. So the actual blast pressure was less than thatpredicted using CONWEP3.

Baylot7, 8et al. and Dennis7 et al. conducted numerous experiments to predict the maximum static capacity of CMU (concrete masonry unit)walls, utilizing 1/4 scale models of $20.32 \mathrm{~cm}$ wide CMU. Lower bound properties were also used to estimate the load deflection function. Experiments were done on grouted and partially grouted walls, where three types of furnishing schemes were used. In the 1st scheme 0.04 in $1 \mathrm{~mm}$ thickness GFRP material attached to the back facade of the wall was used. In the 2nd scheme a two part sprayed on polyurea product was applied to the backside of the wall. For the 3rd technique a twenty gauge galvanized sheet made of steel was bonded to the backside of the wall.During the tests the structures collapsed but the walls retrofitted with polyurea and GFRP successfully precluded the flying debris from spreading away from the structure whereas the galvanized steel retrofitted wall was not able to prevent the loose fragments within the structure. So it was concluded that GFRP and polyurea are successful retrofits. In some cases finite element analysis predicted that the structure would not fail but when the experiment was conducted the wall failed, so this suggests that there may be considerable variability in results of the finite element analysis and actual experiment5.

\subsubsection{Fiber-Reinforced Polyurea or Polyurethane or Unreinforced Masonry Wall}

Knox4 et al. used unreinforced polymers having exceptional ductility like polyurethane and polyurea. These polymers were sprayed on the back of concrete block walls and was successfully able to prevent deadly wall fragmentation.

Baylot7, 8 et al. and Dennis7 et al. performed tests on CMU walls using 1/4 scale and discovered that a 2 part sprayed on polyurea product on the backside of the wallsuccessfully precluded the flying debris from spreading away from the structure.

Hammons4 et al.also applied polyurea to CMU walls and ascertained it to be very successful in preventing wall fragmentation.

Davidson6 et al. conducted explosive tests on polymer reinforced masonry walls, he used spray overlap of 6 in.152 $\mathrm{mm}$ to channel the loads to the frame. It was found that the spray materials provided better bondage, anchorage to the frame and at the same time it was more economical than stiff FRP reinforcing. Continuous fibers have the potential to supply some extra energy dissipation up to fiber rupture. However before providing continuous fiber the additional monetary value required needs to be evaluated against the limited increase in blast resistance.

\subsection{Concrete Structures}

Construction materials can be generically classified into natural raw materials (steel,glass, and sand, fine and coarse aggregate) and admixtures or low weight materials like composites and foams4.The natural materials do not affect the reflection or deflection of blast waves but low weight substances like composites, polymeric foams result in lesser summit reflected overpressure9, 10. Hence the latter of the two can be used in a wide range of structures designed for palliating blasts.

\subsubsection{Sacrificial Wall against Detonation}

Sacrificial blast wall is a defensive block that keeps a structure safe from blasts. The wall is constructed around the structure to protect it from blast waves by disintegrating the energy generated from the explosion. It also increases the bomb threat standoff distances. So the pressures generated during blasts are annihilated completely or lessened in intensity. During the blast the wall may detriment completely but the target structure should be secure and running well following the blast. Match stem is conglutination of incident wave generated from blast and the wave reflected from ground surface at a point above the earth surface. While designing sacrificial blast wall sufficient emphasis should be given on the point that it should not allow the formation of Match stem1.

\subsubsection{Concrete Column}

The effect of the blast is predominant on the columns in the structure, lateral restriction of columns can enhance their load bearing and load deflection capacity. The columns may be retrofitted by steel jackets or by FRP composites. The performance of FRP composites which are extensively used need to be studied under different conditions9, 10 .

Malvar4 et al.studied the use of composite materials to retrofit concrete. Composite materials may be in the form of FRP wraps to increase the lasting capacity of the structures when exposed to blast loads and also limit the flying debris or residues. For improving the blast resistance of the structure the blast resistance of the key structural elements such as columns, bearing walls has been increased 4 .

Cromwell9, 11 et al. performed experiments to investigate the conduct of 3 FRP systems exposed to 9 different environmental conditions. Four different experimental techniques were used. It was found that CFRP plate excelled in all the different conditions. Manually placed up CFRP material stood out well but showed growth in energy assimilation at higher temperatures due to matrix degradation. Manually placed up GFRP material executed like the CFRP fabric but a marked debasement was observed for saline water and alkaline environmental conditions. So both these conditions were considered to be harmful for the glass fiber. Impairment of the structure was observed to be more prominent on the properties of the bond 11 .

Malvar10 et al. (2004) studied columns retrofitted by steel jackets and FRP composites using numerical modeling and comparing the data obtained with actual tests. It was concluded that FRP wraps utilized for retrofitting columns are effective to increase the endurance of buildings exposed to blast loads. 


\subsubsection{Concrete Wall and Slab}

Bearing walls and columns are the fundamental structural components of a building, failure of these components may result in crumble of the structure. Composites can be used to fortify concrete numerous studies have been conducted to test the effectiveness of composites in concrete to resist blast loads.

Muszynski4analyzed unreinforced walls and CFRP or AFRP reinforced walls submitted to blast loadings. It was observed that the walls reinforced with CFRP broke down due to composite bust at mid elevation of the wall.

In case of reinforced walls the flying debris were less than unreinforced walls.

12Muszynski and Purcell applied a sterilized three layered carbon epoxy laminate and an entwined biaxial E-glass material to increase the strength of walls. The reinforced walls lastedfor displacements up to $8.1 \mathrm{~cm}$ which is about forty percent of the depth.

Lawver4et al.investigated the blast resistance offered by concrete slabs retrofitted with composites. Seven no of experiments were done on $6100 \mathrm{~cm}$ on base slabs retrofitted with GFRP or CFRP composites. The results of the experiments depicted that composite retrofits are effective in blast resistant designs.

Lu4 et al.retrofitted 120x120x9 cm3 slabs by using CFRP and SRP (high-strength steel chord reinforced polymer SRP laminates) on both sides. He found that these retrofits enhanced the blast resistance.

\subsection{Steel Structures}

Innovative methods are being used and tested for improving blast resistance of steel structures.

Numerous experiments and tests are conducted on sandwich panels, passive dampers, steel plate shear walls and other mechanisms to study and improvise the blast resistance.

Warn19 et al. coupled the results of nonlinear Finite element analysis with the blast defense anticipated by theory of yield line for testing two representative Steel Plate Shear Wall designed for seismic loading. The latter theory was found to be inappropriate for the Steel Plate Shear Wall (SPSW) utilized in the test. Suitable explosives equivalent to vehicle explosion menace and manually placed bombs were used for testing. The maximum deflection was discovered at the center of the plate. The test showed that the ability of the SPSW to resist the blast load is more dependent on the connection between the infill plate and frame then the ductileness of the infill plate.

Bewick18 et al.performed several experiments to study the effectiveness of various conventional techniques in improving the blast resistance of steel stud walls. It was observed that the use of orthodox methods (like single screw) are not effective in increasing the tensile strength of the membrane, However on using multiple screws the systems were able to attain tensile membrane response. It was concluded that on applying sheaths the endurance of the wall was increased, but on the application of surplus screws in the connection of stud and track, the ductility of the system can be enhanced.

\subsubsection{Passive Dampers}

Passive dampers are usually used to palliate earthquake vibrations. Due to the cyclical nature of the seismic waves the dampers may return back to their original position at the end of the earthquake. But in case of blast loading if a structure with eminent sidelong flexibility, is fitted with high yield force passive dampers, the absorbers can disintegrate a significant portion of the interior energy. The structure undergoes elastic deformation, however the frames of the damper do not return back to their original position so after the blast the structure remains in its averted form. Technically UPD has three main parts, first one is Tube inversion device as energy dissipater, and the constant yield force of the tube inversion device is a substantial advantage as it can be modelled as an elasto-plastic bilinear curve. The diameter, material and the thickness of the tube inversion device affects the yield force of the tube inversion device. The yield force can be calculated on the basis of some assumptions using the formulae.

The assumptions are thickness of the inversion tube remains constant during the inversion of a tube, so that the energy is dissipated in two stages namely bending and unbending of the tube and increasing the diameter of the tube.

The second part of UPD is Connection set for connecting of the dissipater to the structure. It connects the tube inversion device to the braces of the structures. Wedge mechanism may be utilized in the connection set. A connection set in which the wedge mechanism is used.

The damper shows no resistance when compressive loading is applied as a result of which the damping arrangement is able to contract itself when subjected to compressive loading at the same time counterbalancing its deformation after dissipation of energy. Only one of the wedges was allowed to move outward during the compressive loading because a steadfast engagement may not be created within the system when employed force changes rapidly from compressive to tensile.

The third part of UPD is complementing elements for providing the system with unidirectional performance. The complementing elements are a spring, a compression release cap and an initial length limiter. When the structure moves away from its initial equilibrium condition then these complementing elements employs loading to the structure17.

Monir17 studied the effectiveness of UPD in absorbing blast loads, by numerical analysis he discovered that the damper absorbed 10 times more blast energy than the frame and also remained in the elastic state. 


\subsubsection{Sandwich Structure}

Sandwich structures are light weight, have excellent flexural properties, sufficiently stiff, imbibe large amount of energy16. Due to these properties they are preferred over steel plates of equal mass and are thus used for manufacture of navy ships for resisting under water blasts 15 .

Andrews and Moussa14 prepared failure mode maps for lightweight sandwich panels with composite faces. The maps sheet were prepared by describing the face sheet characteristics like aspect ratio of the panel, the core material(e.g. foam) but the geometry and core density were subject to variation. The maps can be used to compare numerous designs, the maps were conjugated with single-degree-of-freedom mass spring model for the inclusion of dynamic effects. A FORTRAN program was used for imitating the effect of blast loading on the panels including the mode of failure and the degree of deformation for a given blast data inputted by the user. The model thus obtained was verified with experimental data.

Karagiozova13et al. performed finite element analysis to study the characteristics of clamped sandwich panels. It was shown that cellular corporeal can be used as an effective core material in sandwich panels, for resisting blast by controlling the transferred load. The variables which determine the characteristics of the structure were ordered and favorable sandwich configuration was made considering the worst case.

\section{CONCLUSION}

Blast loading and blast resistance techniques used in structures are discussed in this paper. The important parameters of blast loadings like Strain Rate Effect, Natural Period, and Dynamic Load Factor of Vibration were studied. Different blast resistant techniques used in masonry, concrete and steel structures were studied and following conclusions can be drawn from the studies:

FRP used in masonry walls were found to be effective in resisting blast, polyurea and GFRP retrofits were found to be successful in preventing wall fragmentation, polyurea sprays has the capability of channelizing the load to the frame.

Composite retrofits and FRP retrofits were found to increase the endurance of the structure against blast and also prevent fragmentation. CFRP, SRP and GFRP retrofits were also found to effectively resist blast. But the performance of the GFRP system deteriorated when exposed to saline or alkaline conditions.

SPSWs have the ability to resist blast, dampers were found to absorb considerable amount of blast load, sandwich structures which have low weight and excellent flexural properties are being applied in a wide range of structures.

\section{REFERENCES}

[1] Goel, M. D. and Matsagar, V. A. "Blast-Resistant Design of Structures", the Practice Periodical on Structural Design and Construction, 19 (2014)

[2] Browning, R.S.,Dinan, R. J. and Davidson, J. S. "Blast Resistance of Fully Grouted Reinforced Concrete Masonry Veneer Walls", Journal Of Performance Of Constructed Facilities, 28 (2014) p.p 228-241

[3] Tan, K. H. and Patoary, M. K. H. "Blast Resistance of FRP-Strengthened Masonry Walls. I: Approximate Analysis and Field Explosion Tests", Journal Of Composites For Construction, 13 (2009) p.p 422-430

[4] Malvar, L. J., Crawford, J. E. and Morrill, K. B. "Use of Composites to Resist Blast", Journal Of Composites For Construction, 11 (2007) p.p 601-610

[5] S.T. Dennis, S.T., Baylot, J.T. and Woodson, S.C.,"Response of 1Õ4-Scale Concrete Masonry Unit (CMU) Walls to Blast", Journal Of Engineering Mechanics, 128 (2002)p.p 134-142

[6] Davidson, J. S., Fisher, J. W., Hammons, M. I., Porter, J. R., and Dinan, R. J., "Failure Mechanisms of Polymer-Reinforced Concrete Masonry Walls Subjected to Blast", Journal Of Structural Engineering, 131 (2005) p.p 1194-1205

[7] Dennis, S.T.,Baylot, J.T. and Woodson, S.C., "Response of 1/4Scale Concrete Masonry Unit (CMU) Walls to Blast", Journal Of Engineering Mechanics, 128 (2002) p.p 134-142

[8] Baylot, J. T., Bullock, B., Slawson, T.R., and Woodson, S.C. "Blast Response of Lightly Attached Concrete Masonry Unit Walls", Journal Of Structural Engineering, 131 (2005) p.p 1186-1193

[9] Cromwell, J.R., Harries, K.A. and Shahrooz, B.M. "Environmental durability of externally bonded FRP materials intended for repair of concrete structures", Construction and Building Materials, 25 (2011) p.p 2528-2539

[10] Malvar, L. J., Morrill, K. B. and Crawford, J. E. "Numerical Modeling of Concrete Confined by Fiber-Reinforced Composites", Journal Of Composites For Construction, 8 (2004) p.p 315-322

[11] Cromwell, J.R., Harries, K.A. and Shahrooz, B.M. "Environmental durability of externally bonded FRP materials intended for repair of concrete structures", Construction and Building Materials, 25 (2011) p.p 2528-2539

[12] Muszynski, L. C. and Purcell, M.R. "Use of Composite Reinforcement to Strengthen Concrete and Air-Entrained Concrete Masonry Walls against Air Blast", Journal Of Composites For Construction, 7 (2003) p.p 98-108

[13] Karagiozova, D., Nurick a, G.N. and Langdon, G.S. "Behaviour of sandwich panels subject to intense air blasts - Part 2: Numerical simulation”, Composite Structures, 91 (2009) p.p 442-450

[14] Andrews, E.W. and Moussa, N.A. "Failure mode maps for composite sandwich panels subjected to air blast loading", International Journal of Impact Engineering, 36 (2009) p.p 418-425 
[15] Hassan, M.Z., Guan, Z.W., Cantwell, W.J., Langdon, G.S. and Nurick, G.N. "The influence of core density on the blast resistance of foam-based sandwich structures", International Journal of Impact Engineering, 50 (2012) p.p 9e16

[16] Deshpande, V.S. and Fleck, N.A. "Isotropic constitutive models for metallic foams", Journal of the Mechanics and Physics of Solids, 48 (2000) p.p 1253 \pm 1283

[17] Monir, H. S. "Flexible blast resistant steel structures by using unidirectional passive dampers", Journal of Constructional Steel Research, 90 (2013) p.p 98-107
[18] Bewick, B. T., O’Laughlin, C. G. andWilliamson, E. B. "Evaluation of Conventional Construction Techniques for Enhancing the Blast Resistance of Steel Stud Walls", Journal Of Structural Engineering, 139 (2013) p.p 1992-2002

[19] Warn, G. P. and Bruneau, M. "Blast Resistance of Steel Plate Shear Walls Designed for Seismic Loading", Journal Of Structural Engineering, 135 (2009) p.p $1222-1230$

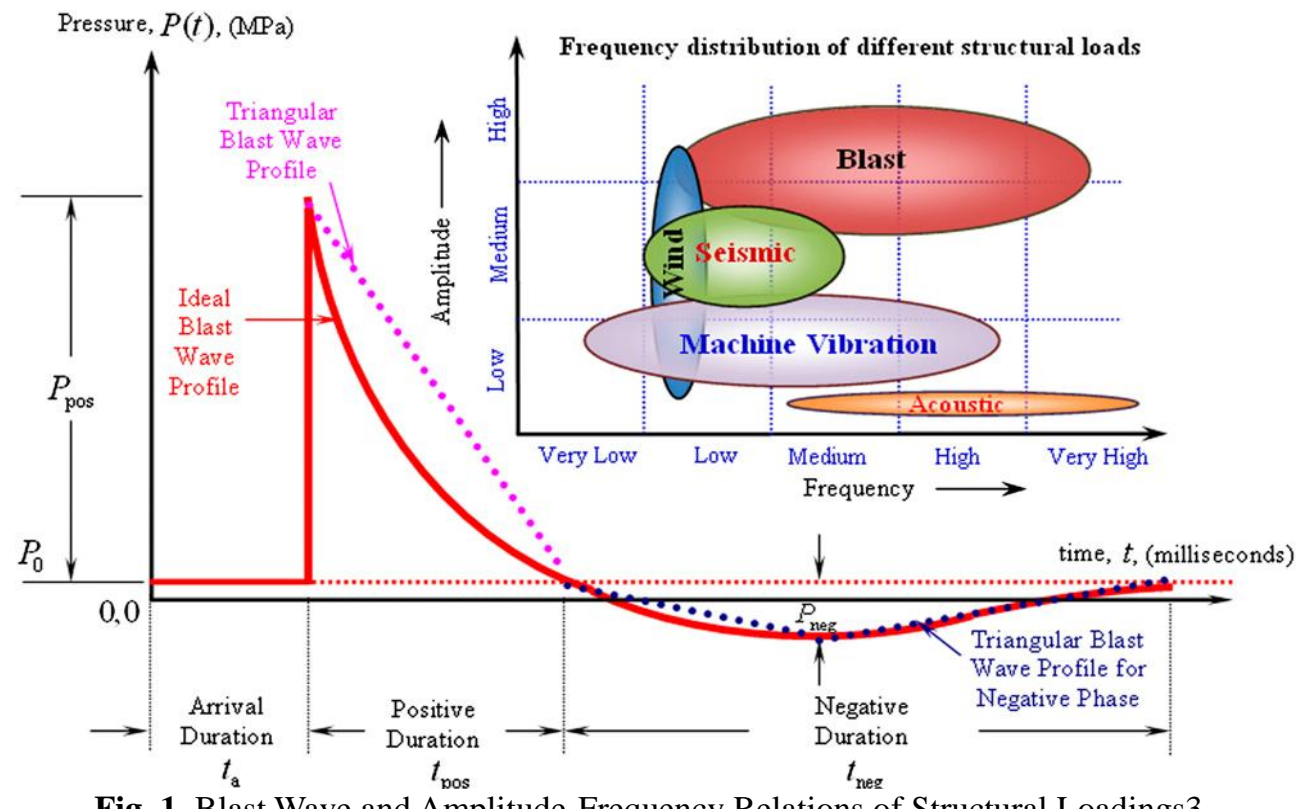

Fig. 1. Blast Wave and Amplitude-Frequency Relations of Structural Loadings 3

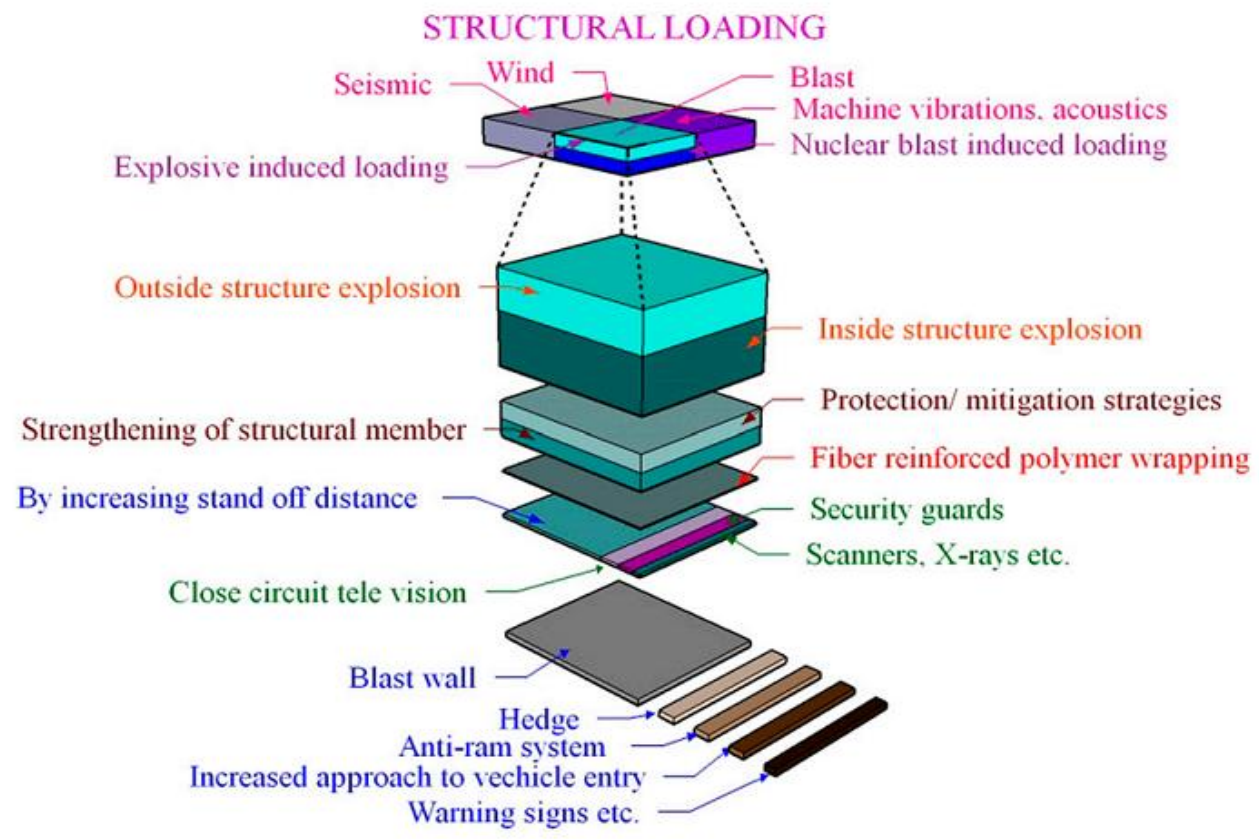

Fig. 2. Pictorial Representation of Different Loadings on Structure and Strategies Adopted For Blast Mitigation3 